\title{
Redox Balance and Carbonylated Proteins in Limb and Heart Muscles of Cachectic Rats
}

\author{
Judith Marin-Corral,,2 Cibely C. Fontes, ${ }^{1}$ Sergi Pascual-Guardia,, ${ }^{1,2}$ Francisco Sanchez,, ${ }^{1,2}$ Mireia Olivan, ${ }^{3}$ \\ Josep M. Argilés, ${ }^{3}$ Sílvia Busquets, ${ }^{3}$ Francisco J. López-Soriano, ${ }^{3}$ and Esther Barreiro ${ }^{1,2}$
}

\begin{abstract}
In fast- and slow-twitch limb and heart muscles of cachectic rats, redox balance and muscle structure were explored. The nature of the oxidatively modified proteins also was identified in these muscles. Reactive carbonyls, hydroxynonenal (HNE)- and malondialdehyde (MDA)-protein adducts, and antioxidant enzyme levels were determined in limb and heart muscles of cachectic (7 days after inoculation of Yoshida AH-130 ascites hepatoma) and control rats. Moreover, carbonylated proteins were identified (proteomics), and fiber-type composition evaluated (morphometry) in these muscles. In cachectic rats, compared with the controls: (a) HNE- and MDAprotein adducts levels were greater in gastrocnemius, tibialis anterior, soleus, and heart; (b) in the gastrocnemius, type II fiber size was reduced, and the intensity of carbonylated protein immunostaining was significantly greater in these fibers; and (c) proteins involved in glycolysis, ATP production and distribution, carbon dioxide hydration, muscle contraction, and mitochondrial metabolism were significantly more carbonylated in limb and heart muscles. Cancer cachexia alters redox balance in fast- and slow-twitch limb and heart muscles of rats, inducing increased oxidative modifications of key proteins involved in muscle structure and function. Additionally, it induces a reduction in type II fiber size in the gastrocnemius, which is associated with increased protein oxidation. Antioxid. Redox Signal. 12, 365-380.
\end{abstract}

\section{Introduction}

$\mathbf{I}_{\mathrm{b}}^{\mathrm{N}}$

ADVANCED MALIGNANT DISEASES, cachexia appears to be one of the most common systemic manifestations. The presence of cachexia always implies a poor prognosis, having a great impact on the patients' quality of life and survival (17). Several important molecular mechanisms have been shown to be involved in the increased muscle catabolism observed in cancer-induced cachexia, such as greater ubiquitinproteasome-dependent proteolysis, apoptosis, and activation of uncoupling proteins $(1,2,42,47)$. Interaction of these mechanisms leads to muscle-mass loss by promoting protein and DNA breakdown and energy inefficiency.

In skeletal muscles, reactive oxygen and nitrogen species (ROS and RNS, respectively) are normally synthesized at low levels and are required for normal force production (36-38). However, they may overwhelm tissue antioxidant capacity when produced at high levels, thus leading to oxidative stress.
Oxidative imbalance has been shown to be involved in several models of cancer-induced cachexia $(3,12,16,30)$, as well as in immobilization-induced muscle atrophy (35). Proteins are major targets of oxidative stress-derived effects on tissues (3, $4,7,10,11,14,35,50)$. Importantly, the oxidative posttranslational modifications of proteins may cause loss of protein function as a result of oxidation of residues in the protein active site. In other cases, oxidation of critical residues may also lead to increased proteolytic degradation of the modified proteins (44). It was recently suggested that the ROS cascade regulates pathophysiologic signaling, leading to proteolysis and apoptosis when synthesized at high levels within the myofibers (35).

In a previous study (3), we showed that increased oxidative stress was associated with cancer-induced cachexia in the gastrocnemius muscles of rats. In that study, however, the nature of the oxidatively modified proteins or the levels of protein oxidation in muscles other than the gastrocnemius were not

\footnotetext{
${ }^{1}$ Pulmonology Department, Muscle and Respiratory System Research Unit (URMAR), IMIM-Hospital del Mar, Department of Experimental Sciences and Health, Universitat Pompeu Fabra, School of Medicine, Universitat Autònoma de Barcelona, Barcelona Biomedical Research Park (PRBB), Barcelona, Spain.

${ }^{2}$ Centro de Investigación en Red de Enfermedades Respiratorias (CIBERES), Instituto de Salud Carlos III (ISCIII), Bunyola, Majorca, Balearic Islands, Spain.

${ }^{3}$ Departament de Bioquímica i Biologia Molecular, Facultat de Biologia, Universitat de Barcelona, and Institut de Biomedicina de la Universitat de Barcelona (IBUB), Barcelona, Spain.
} 
investigated. In addition, muscle structure was not explored in that study (3). On this basis, it is now hypothesized that excessive ROS production in fast- and slow-twitch limb and heart muscles of cachectic animals will target key proteins involved in muscle structure and function, which may eventually render them more susceptible to greater protein catabolism. Furthermore, in the present study, we also investigated whether increased oxidative stress in cancer-induced cachexia is muscle or fiber type specific or both. In the current investigation, the ascites hepatoma Yoshida AH-130, a wellvalidated model characterized by a rapid and progressive loss of body weight and muscle mass (23), was used to induce cancer cachexia in rats. According to this hypothesis, our main objectives were established as follows: (a) to explore whether increased oxidative stress occurs in different fast- and slowtwitch limb and heart muscles of cachectic rats; (b) to identify the nature of the oxidatively modified proteins (protein carbonylation indices) in the limb and cardiac muscles of both tumor-bearing and control rats, (c) to investigate whether carbonylation levels in each identified protein are differentially regulated in the cachectic limb and cardiac muscles; (d) to assess muscle fiber structure in fast- and slow-twitch limb muscles of both groups of animals; and (e) to evaluate the possible existence of a fiber-type specificity of protein oxidation within the limb muscles of the cachectic rats.

\section{Materials and Methods}

\section{Animal experiments}

All animal experiments were conducted at Facultat de Biologia, Universitat de Barcelona. This was a controlled study designed in accordance with both the ethical standards on animal experimentation in our institution (EU 609/86 CEE and Real Decreto 1201/05 BOE 252, Spain) and the Helsinki convention for the use and care of animals. All experiments were approved by the institutional Animal Research Committee (Universitat de Barcelona).

Male Wistar rats (Interfauna, Barcelona, Spain), of $\sim 6$ weeks of age, were used in the different experiments. The animals were maintained at $22 \pm 2{ }^{\circ} \mathrm{C}$ with a regular lightdark cycle (light on from 08:00 a.m. to 08:00 p.m.) and had free access to food and water. The diet (B.K. Universal G.J./ S.L., Sant Vicenç del Horts, Barcelona, Spain) consisted of $45.5-48.5 \%$ carbohydrate $(3.5 \%$ absorbable glucose, $42-45 \%$ starch), $18.5 \%$ protein, and $3.1 \%$ fat (the residue was nondigestible material). The food intake was measured daily. Rats were divided into two groups: (a) controls $(n=7)$ and (b) tumor-bearing hosts $(n=7)$. The latter received an intraperitoneal inoculum of $10^{8} \mathrm{AH}-130$ Yoshida ascites hepatoma cells obtained from exponential tumors (46). On day 7 after tumor transplantation, the animals were weighed and anesthetized with an IP injection of ketamine/xylazine mixture (3:1; Imalgene and Rompun, respectively). The tumor was harvested from the peritoneal cavity, and its volume and cellularity evaluated. Moreover, gastrocnemius, tibialis anterior (TA), extensor digitorum longus (EDL), soleus, and heart muscles were obtained from both tumor-bearing and control animals. A piece of the muscle specimens was immediately frozen in liquid nitrogen and subsequently stored at $-80^{\circ} \mathrm{C}$, whereas the other piece was immersed in an alcohol-formol bath for $2 \mathrm{~h}$, thereafter to be embedded in paraffin. Frozen tissues were used for the analyses of redox balance and for protein identification (immunoblotting and proteomics analyses), whereas morphometric analyses and localization of protein carbonylation markers were evaluated on the paraffinembedded tissues (immunohistochemical analyses).

\section{Muscle biology analyses}

All the muscle-biology experiments were conducted blind in the same laboratory, at Hospital del Mar-IMIM-Universitat Pompeu Fabra (Barcelona).

Detection of reactive carbonyls in muscle proteins. Changes in protein carbonylation in crude muscle homogenates were detected by using the commercially available Oxyblot kit (Chemicon International, Inc., Temecula, CA). Carbonyl groups in the protein side chains were derivatized to 2,4-dinitrophenylhydrazone (DNP) by reaction with 2,4dinitrophenylhydrazine (DNPH) according to the manufacturer's instructions. In brief, $15 \mu \mathrm{g}$ of protein was used per derivatization reaction. Proteins were then denatured by addition of $12 \%$ SDS. The samples were subsequently derivatized by adding $10 \mu \mathrm{l}$ of $1 \times \mathrm{DNPH}$ solution and incubated for $20 \mathrm{~min}$. Finally, $7.5 \mu \mathrm{l}$ of neutralization solution and 2mercaptoethanol were added to the sample mixture. The specificity of reactive carbonyl measurements was confirmed by avoiding the derivatization process and by omission of the primary antibody and incubation of the membranes only with secondary antibody [Goat anti-rabbit IgG, horseradish peroxidase (HRP)-conjugated, from the Oxyblot kit; dilution, $1 / 300]$. DNP-derivatized proteins were loaded onto $12 \%$ trisglycine sodium dodecylsulfate polyacrylamide gels (SDSPAGE) and separated with electrophoresis.

Formation of hydroxynonenal- and malondialdehyde (MDA)-protein adducts. Another mechanism of protein carbonylation is by the reaction of certain amino acids with unsaturated aldehydes generated during the peroxidation of polyunsaturated fatty acids. Lipid-derived aldehydes such as HNE and MDA can thus cause further cellular damage by binding to and modifying proteins, which leads to the formation of stable aldehyde-protein adducts. HNE reacts with lysine, cysteine, and histidine residues of proteins to form Michael adducts, whereas MDA reacts with lysine residues to form Schiff base adducts (39-41).

Immunoblotting of 1D electrophoresis. The effects of ROS and RNS on muscle proteins were evaluated according to methods published elsewhere $(3-7,10,11)$. Frozen muscle specimens from both tumor-bearing and control animals were homogenized in a buffer containing $N$-2-hydroxyethyl piperazine- $N^{\prime}$-2-ethanesulfonic acid (HEPES), $50 \mathrm{mM} ; \mathrm{NaCl}$, $150 \mathrm{mM}$; NaF, $100 \mathrm{mM}$; Na pyrophosphate, $10 \mathrm{mM}$; ethylenediaminetetraacetic acid (EDTA), $5 \mathrm{mM}$; Triton- $\mathrm{X}, 0.5 \%$, leupeptin, $2 \mu \mathrm{g} / \mathrm{ml}$; phenylmethylsulphonyl fluoride (PMSF), $100 \mu \mathrm{g} / \mathrm{ml}$; aprotinin, $2 \mu \mathrm{g} / \mathrm{ml}$; and pepstatin $\mathrm{A}, 10 \mu \mathrm{g} / \mathrm{ml}$. Samples were then centrifuged at 1,000 $\mathrm{g}$ for $30 \mathrm{~min}$. The pellet was discarded, and the supernatant was designated as a crude cytoplasmic homogenate. Protein levels in each homogenate were spectrophotometrically determined with the Bradford technique by using triplicates in each case and bovine serum albumin (BSA) as the standard (Bio-Rad protein reagent; BioRad Inc., Hercules, CA). The final protein concentration in 
each sample was calculated from at least two Bradford measurements that were almost identical. Equal amounts of total protein from crude muscle homogenates were always loaded ( $20 \mu \mathrm{g}$ per sample/lane) onto the gels, as well as identical sample volumes/lanes.

Five totally independent sets of experiments were conducted for each muscle (gastrocnemius, TA, EDL, soleus, and heart) from both tumor-bearing and control animals, in which oxidative stress markers and antioxidant mechanisms were explored. For the purpose of comparisons between the two groups of rats in each muscle, sample specimens were always run together and kept in the same order. Proteins were then separated with electrophoresis (SDS-PAGE), transferred to polyvinylidene difluoride (PVDF) membranes, blocked with nonfat milk, and incubated overnight with selective antibodies. The following antibodies were used to detect indices of protein carbonylation and nitration and antioxidant mechanisms: anti-DNP moiety antibody (rabbit anti-DNP antibody from the Oxyblot kit; dilution, 1:150), anti-HNEprotein adducts (Alpha Diagnostic International, San Antonio, TX; dilution, 1:2,000), anti-MDA-protein adducts antibody (Academy Bio-Medical Company, Inc., Houston, TX; dilution, 1:4,000), anti-Mn SOD antibody (StressGen, Victoria, BC, Canada; dilution, 1:5,000), and anti-catalase antibody (Calbiochem, San Diego, CA; dilution, 1:2,000). Tissue homogenates obtained from rat brain mitochondria and rat erythrocytes were used as positive controls of the enzymes Mn-SOD and catalase, respectively. Specific proteins from all samples were detected with HRP-conjugated secondary antibodies and a chemiluminescence kit. For each of the antigens, samples from the two groups of rats in each muscle were always detected in the same film under identical exposure times. The specificity of the different antibodies was confirmed by omission of the primary antibody and incubation of the membranes only with secondary antibodies. Blots were scanned with an imaging densitometer, and optical densities of specific proteins were quantified with Diversity Database 2.1.1 (BioRad, Philadelphia, PA). Values of total reactive carbonyl groups, total HNE-protein adducts, and total MDAprotein adducts in a given sample were calculated by addition of optical densities (arbitrary units) of individual protein bands in each case. Final optical densities obtained in each group of rats for each muscle corresponded to the mean values of the different samples (lanes) of each of the antigens studied.

To validate equal protein loading among various lanes, SDS-PAGE gels were stained with Coomassie Blue and PVDF membranes with Ponceau red staining.

Identification of carbonylated muscle proteins: 2D electrophoresis. Carbonylated proteins (containing reactive carbonyl groups) were separated and identified in gastrocnemius, TA, EDL, soleus, and heart muscles of both tumorbearing and control rats. Moreover, MDA-protein adducts spots were also identified in all these muscles. The procedures followed in these experiments were previously published $(8-10,26)$. In brief, 4 volumes of $10 \mathrm{mM} \mathrm{2,4-}$ dinitrophenylhydrazine (DNPH) were first added (reactive carbonylated proteins) to crude muscle homogenates (400 $\mu \mathrm{g}$ protein/sample) and incubated for $30 \mathrm{~min}$ at room temperature to identify carbonylated proteins specifically. The reaction was stopped by adding the neutralization solution. In both cases, crude muscle homogenates (400 $\mu \mathrm{g}$ protein/ sample) were prepared for 2D-electrophoresis with the 2D Clean up kit (Amersham Biosciences, Piscataway, NJ) by following the manufacturer's instructions. The samples were then incubated for $15 \mathrm{~min}$ on ice, centrifuged for $5 \mathrm{~min}$ at $13,000 \mathrm{~g}$, and the pellets were then washed 3 times and centrifuged at $13,000 \mathrm{~g}$ for $5 \mathrm{~min}$. The pellets were resuspended in 2D re-hydration buffer $\{8 M$ urea, 2\% 3-[(3-cholamidopropyl)dimethylammonio]-1-propanesulfonate (CHAPS), $20 \mathrm{mM}$ dithiothreitol (DTT), and $0.002 \%$ bromophenol blue\}. Each muscle sample was then separated into two portions $(200 \mu \mathrm{g}$ total each), and both portions underwent 2-D electrophoresis. First-dimensional protein separation was performed with the Ettan IPGPhor 3 (GE Healthcare Biosciences AB, Uppsala, Sweden). Samples were applied to immobilized $\mathrm{pH}$ gradient (IPG) strips (18-cm nonlinear, $\mathrm{pH} 3$ to 10; GE Healthcare Biosciences $\mathrm{AB}$ ) for $30 \mathrm{~min}$ at room temperature. The strips were then covered with mineral oil overnight, and isoelectric focusing was performed at a maximum of $10,000 \mathrm{~V} / \mathrm{h}$ for up to a total of 35,200 V-h.

For the second dimension, the IPG strips were equilibrated at room temperature for $30 \mathrm{~min}$ in equilibration buffer $(6 \mathrm{M}$ urea, $2 \%$ SDS, $50 \mathrm{mM}$ Tris- $\mathrm{HCl}, 30 \%$ glycerol, and $0.002 \%$ bromophenol blue), to which $1 \%$ DTT was added before use. An additional 30-min equilibration period was then used with equilibration buffer to which $2.5 \%$ iodoacetamide was added. The strips were then embedded in $0.5 \%$ agarose on the top of $30 \%$ acrylamide gels. The second-dimension SDS/PAGE was performed for $5 \mathrm{~h}, 70 \mathrm{~mA}$ per gel, at $250 \mathrm{~V}$. One of the resulting 2D gels for each muscle sample was then stained with silver stain. Gels were fixed overnight in a fixation solution $(50 \%$ acetic acid, 50\% methanol), then rinsed twice in water, sensitized for $1 \mathrm{~min}$ in $0.2 \%$ sodium thiosulfate, followed by rinsing in water and immersion for $30 \mathrm{~min}$ in a silver nitrate solution ( $2 \%$ silver nitrate). Gels were then rinsed twice in water and developed in a developer solution (20\% sodium carbonate, $0.05 \%$ formaldehyde, $0.004 \%$ sodium thiosulfate). A stop solution ( $6 \%$ acetic acid) was then added for $15 \mathrm{~min}$, followed by rinsing with water for $5 \mathrm{~min}$. Gels were then stored in $1 \%$ acetic acid. The second gel derived from a given sample underwent electrophoretic transfer to PVDF membrane and immunoblotting with anti-DNP antibody or antiMDA-protein adducts antibody, as described earlier. Gels and PVDF membranes were imaged with a digital camera and aligned (Adobe Photoshop 8.0.1, San Jose, CA) so as to identify positive spots of either carbonylated proteins or MDAprotein adduct on the gels. Optical densities (arbitrary units) of the immunoblot spots corresponding to each oxidatively modified protein were measured in each muscle of both groups of animals by using Quantity One analysis software 4.6.5 (BioRad, Philadelphia, PA).

Identification of carbonylated proteins and MDA-protein adducts: mass spectrometry. This was conducted in the Proteomics Laboratory at Universitat Pompeu Fabra by following the quality criteria established by ProteoRed standards (Instituto Nacional de Proteómica, Spain) and procedures previously published $(8-10,26)$. Protein carbonylated and MDA-protein adduct spots from silver-stained gels were manually excised for in-gel digestion in a 96-well ZipPlate placed in a Multiscreen vacuum manifold (Millipore, Billerica, $\mathrm{ME})$. Proteins were reduced, alkylated, and digested with 
sequence-grade trypsin (Promega, Madison, WI). Peptides were eluted with $15-25 \mu$ l of $0.1 \%$ trifluoroacetic acid (TFA) in $50 \%$ acetonitrile $(\mathrm{ACN})$. Then $2.5 \mu \mathrm{l}$ of tryptic digest was deposited onto Mass Spec Turbo 192 type 1 peptide chips pre-spotted with $\alpha$-cyano-4-hydroxycinnamic acid (CHCA) (Qiagen, Germantown, MD) and left for $3 \mathrm{~min}$ for peptide adsorption. Then each spot was washed for $5 \mathrm{~s}$ with $1 \mu \mathrm{l}$ of finishing solution (Qiagen) and left until dried. Matrixassisted laser desorption/ionization time-of-flight (MALDITOF) mass spectrometry (MS) was performed in a Voyager DE-STR instrument (Applied Biosystems, Foster City, CA) by using a 337-nm nitrogen laser and operating in the reflector mode, with an accelerating voltage of $20 \mathrm{kV}$. Samples were analyzed in the $\mathrm{m} / \mathrm{z} 800-3,000$ range and were calibrated externally by using a standard peptide mixture (Sequazyme Peptide Mass Standards kit, Applied Biosystems). Peptides from trypsin autolysis were used for the internal calibration. Protein identification from MALDI-TOF results was done with the MASCOT search engine (Matrix Science, London, UK) by using human proteins available in the SwissProt database as well in the NCBI nonredundant database for the identification of the guinea-pig proteins. Moreover, the following parameters were used for database searches: one missed cleavage allowed, plus Cys carbamidomethylation as fixed and Met oxidation as variable modifications selected, respectively.

Immunohistochemical analyses. Morphometric analyses were carried out in the gastrocnemius, TA, EDL, and soleus muscles from both tumor-bearing and control rats. On 3- $\mu \mathrm{m}$ muscle paraffin-embedded sections, myosin heavy chain-I and -II isoforms were identified by using monoclonal antimyosin heavy chain-I (clone NOQ7.5.4D; Sigma, St. Louis, MO) and monoclonal anti-myosin heavy chain-II antibodies (clone MY-32, Sigma), respectively, as published elsewhere $(4,7,13)$. The cross-sectional area, mean least diameter, and proportions of type I and type II fibers were assessed by using a light microscope (Olympus, Series BX50F3, Olympus Optical Co., Hamburg, Germany) coupled with an imagedigitizing camera (Pixera Studio, version 1.0.4; Pixera Corporation, Los Gatos, CA) and a morphometry program (NIH Image, version 1.60, Scion Corporation, Frederick, MD). At least 150 to 200 fibers were measured and counted in each muscle specimen.

Furthermore, the immunohistochemical localization of reactive carbonyls and MDA-protein adducts was also explored on paraffin-embedded sections of the gastrocnemius, TA, EDL, and soleus muscles by following methods previously published $(5,7,8,11)$. In brief, muscle samples were immersed in subsequent baths of different degrees of alcohol, formol, and xylol, before being embedded in paraffin. Slides were then fixed in amino propyl-triethoxilane and acetone and dried with heat $\left(60^{\circ} \mathrm{C}\right)$. Three-micrometer muscle paraffinembedded sections were obtained by using a microtome. All sections were deparaffinized and incubated with a citric acid solution in a pressure cooker (antigen-retrieval protocol). Carbonyl groups in the protein side chains were derivatized to DNP by reaction with DNPH followed by the addition of $7.5 \mu \mathrm{l}$ of neutralization solution. Sections were then incubated overnight with a polyclonal anti-DNP moiety antibody (1:150). After several washes in phosphate-buffered saline (PBS), slides were incubated for $1 \mathrm{~h}$ with biotinylated secondary antibody (1:300) followed by HRP-conjugated streptavidin and diaminobenzidine as a substrate. Slides were counterstained with hematoxylene, dehydrated, and mounted for conventional microscopy. Aside from those slides that were exposed only to secondary antibodies, slides not subjected to the derivatization process were also used as negative controls.

Moreover, the histologic localization of MDA-protein adducts was conducted by using the anti-MDA-protein adduct antibody (1:20) with immunhistochemical procedures similar to those described earlier.

Histologic scoring. The intensity of protein carbonylation and MDA-protein adducts was scored in a semiquantitative manner by using methods similar to those previously published $(27,43)$. In brief, in either type I or type II fibers, positive-stained fibers for both reactive carbonyls and MDAprotein adducts were classified according to the following categories: $0,1+, 2+, 3+$, and $4+(0$ indicating the absence of staining). A minimum amount of 200 fibers was counted in each muscle preparation. The histochemical score (Hscore) for each single fiber in each muscle preparation was calculated blind by two independent observers as follows: percentage of fibers in each category $(\mathrm{P})$ multiplied by the corresponding category (Hscore $1=\mathrm{P} 1 \times 1$; Hscore $2=\mathrm{P} 2 \times 2$; Hscore $3=$ $\mathrm{P} 3 \times 3$; and Hscore $4=\mathrm{P} 4 \times 4$ ); where Hscore 1 was the lowpositive and Hscore 4 was the high-positive grade. Moreover, Hscore 0 was established as the percentage of negative fibers. Final scores in each category were the average of the scores provided by the two independent observers (coefficient of correlation, $r^{2}=0.98$ ). The Hscores were calculated in type I and type II fibers of the gastrocnemius muscle in all tumorbearing and control rats.

\section{Statistical analysis}

Results are presented as mean and standard deviation. Comparisons of the different variables between tumorbearing and control rats for each limb and heart muscle were assessed by using the unpaired Student's $t$ test. The sample size chosen was based on previous studies $(3,5,6,11)$ and on assumptions of $80 \%$ power to detect an improvement of $>20 \%$ in measured outcomes at a level of significance of $p \leq 0.05$.

\section{Results}

\section{Characteristics of the study animals}

Table 1 indicates the main characteristics of tumor-bearing animals. The implantation of the Yoshida AH-130 ascites hepatoma resulted in a decrease in muscle weights on day 7 after tumor transplantation (13\% for gastrocnemius, $10 \%$ for TA, $20 \%$ for EDL, $9 \%$ for soleus, and $20 \%$ for heart).

\section{Muscle redox balance in limb muscles and heart and oxidatively modified proteins}

Oxidative stress markers. Several carbonylated protein bands were identified in all the limb and heart muscles from both tumor-bearing and control rats (Fig. 1A). The pattern of the carbonylated protein bands differed across muscles (Fig. 1A). Total reactive carbonyl groups were significantly increased in the gastrocnemius of tumor-bearing rats com- 
Table 1. Weights of Limb Muscles and Heart OF TUMOR-BEARING RATS

\begin{tabular}{lcc}
\hline Limb muscles and heart & $\begin{array}{c}\text { Control rats, } \\
\mathrm{n}=7\end{array}$ & $\begin{array}{c}\text { Tumor-bearing } \\
\text { rats, } \mathrm{n}=7\end{array}$ \\
\hline Gastrocnemius & $642(56)$ & $567(33)^{\mathrm{a}}$ \\
Tibialis anterior & $205(13)$ & $184(1)^{\mathrm{a}}$ \\
Extensor Digitorum Longus & $50(4)$ & $40(4)^{\mathrm{b}}$ \\
Soleus & $43(2)$ & $39(2)^{\mathrm{a}}$ \\
Heart & $455(31)$ & $373(24)^{\mathrm{b}}$ \\
\hline
\end{tabular}

Results are expressed as mean (SD). Muscle weights are expressed as $\mathrm{mg} / 100 \mathrm{~g}$ of initial body weight.

Statistical significance of the results: ${ }^{\mathrm{a}} p<0.01$ and ${ }^{\mathrm{b}} p<0.001$ (tumorbearing rats compared to control animals). pared with control animals (Fig. 1B). However, no significant differences were observed in total reactive carbonyl group formation between cachectic and control animals in TA, EDL, soleus, or heart muscles (Fig. 1B). Several carbonylated protein spots were identified in the skeletal and heart muscles of both tumor-bearing and control rats (Fig. 1C).

Several HNE-protein adducts bands were identified in all the limb and heart muscles from both tumor-bearing and control rats (Fig. 2A). The pattern of the HNE-protein adduct bands differed across muscles (Fig. 2A). Interestingly, levels of $\mathrm{HNE}$-protein adducts were greater in the gastrocnemius, TA, soleus, and heart of tumor-bearing rats than in control animals (Fig. 2B). Moreover, several MDA-protein adducts bands were identified in all the limb and heart muscles from both tumor-bearing and control rats (Fig. 2C). The pattern of the MDA-protein adducts differed across muscles (Fig. 2C).
A

$\mathrm{MW}(\mathrm{KDa})$

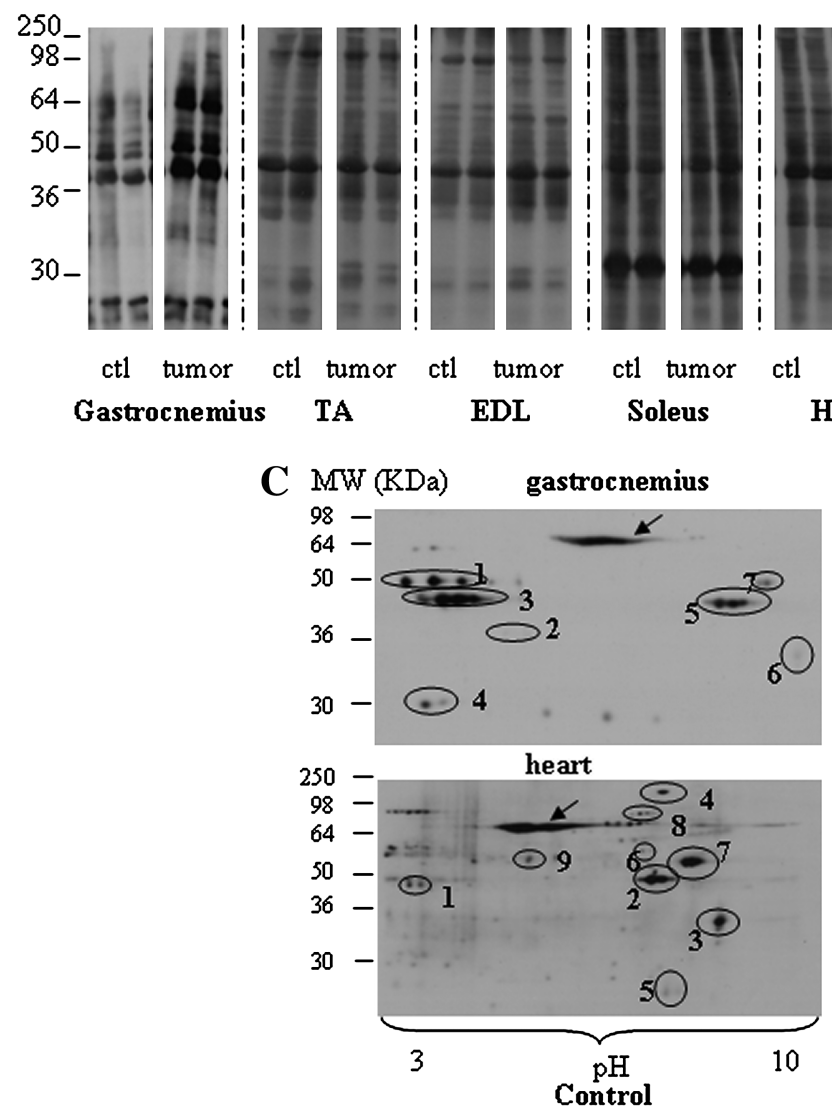

B

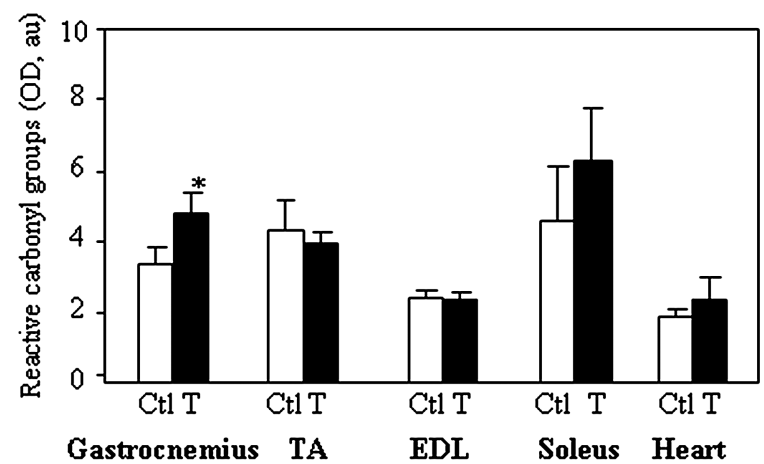

$\mathrm{MW}(\mathrm{KDa}) \quad$ gastrocnemius
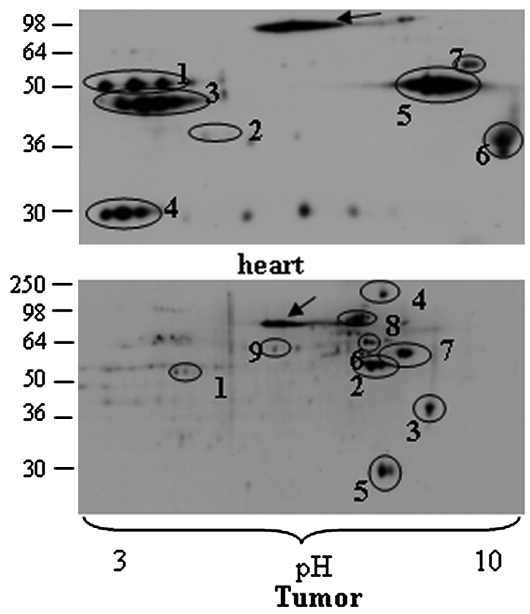

FIG. 1. (A) Representative examples of the different sets of reactive carbonyl immunoblots corresponding to the muscles analyzed in the study: gastrocnemius, TA, EDL, soleus, and heart of tumor-bearing and control rats. Note that the pattern and intensity of the different carbonylated protein bands varied across the different muscles. (B) Mean values and standard deviation of total reactive carbonyls [optical densities (ODs) expressed in arbitrary units (au)] were significantly greater $\left({ }^{*} p<0.05\right)$ only in the gastrocnemius of cachectic rats $(\mathrm{T})$ compared with control animals $(\mathrm{Ctl})$. (C) Representative 2D immunoblots corresponding to the detection of carbonylated proteins in crude muscle homogenates of gastrocnemius (top panels) and heart (bottom panels) of control and cachectic rats (left and right panels, respectively). $\beta$-Enolase (1), fructose biphosphate aldolase A (2), creatine kinase (3), carbonic anhydrase-3 (4), actin (5), tropomyosin (6), and ATP synthase (7) were consistently oxidized in the gastrocnemius of both cachectic and control rats. Moreover, creatine kinase (1), actin (2), tropomyosin (3), myosin-6 (4), myosin light chain (5), vacuolar proton pump (6), ATP synthase (7), NADH-ubiquinone oxidoreductase (8), and aldehyde dehydrogenase mitochondria (9) were consistently oxidized in the hearts of both cachectic and control rats. Albumin was also carbonylated in the muscles of both control and cachectic rats (arrows). 
A $M W(K D a)$

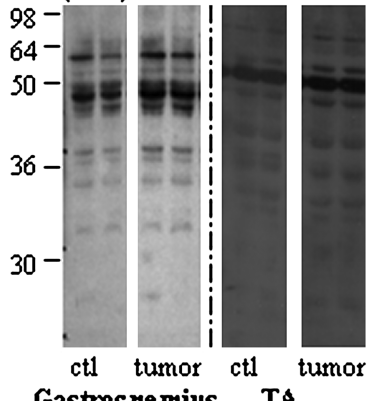

Gastroc ne mius

TA
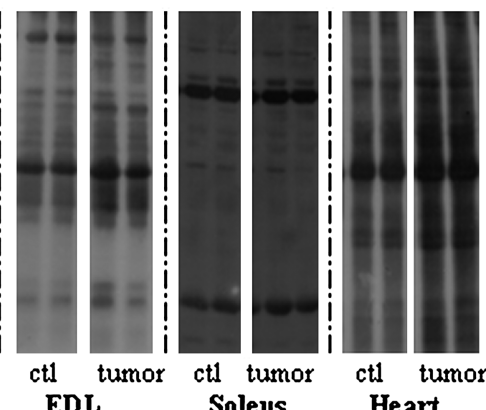

$\mathrm{C} M W(\mathrm{KDa})$
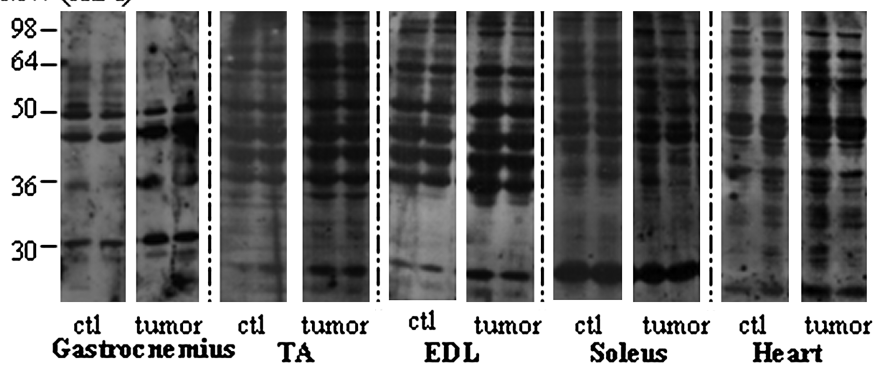

E $\mathrm{MW}(\mathrm{KDa})$
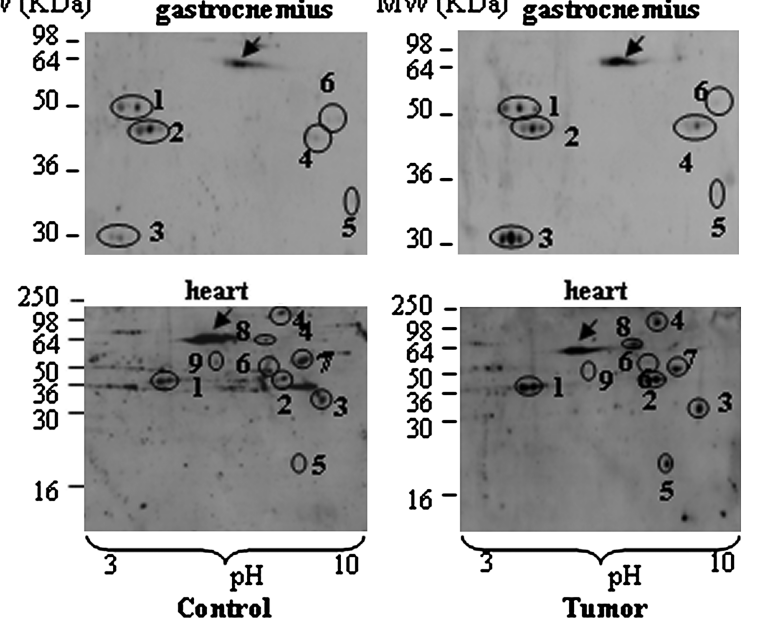

FIG. 2. (A) Representative examples of the different sets of HNE-protein adduct immunoblots corresponding to the muscles analyzed in the study: gastrocnemius, TA, EDL, soleus, and heart of tumor-bearing and control rats. Note that the pattern and intensity of the different HNE-protein adduct bands differed across the different muscles. (B) Mean values and standard deviation of HNE-protein adducts [optical densities (OD) expressed in arbitrary units (au)] were significantly greater $\left({ }^{*} p<0.05\right)$ in the gastrocnemius, TA, soleus, and heart of cachectic rats $(\mathrm{T})$ compared with control animals $(\mathrm{Ctl})$. $(\mathbf{C})$ Representative examples of the different sets of MDA-protein adduct immunoblots corresponding to the muscles analyzed in the study: gastrocnemius, TA, EDL, soleus, and heart of tumor-bearing and control rats. Note that the pattern and intensity of the different MDA-protein adduct bands differed across the different muscles. (D) Mean values (SD) of MDA-protein adducts [optical densities (OD) expressed in arbitrary units $(\mathrm{au})$ ] were significantly greater $\left({ }^{*} p<0.05\right)$ in the gastrocnemius, $\mathrm{TA}$, and heart of cachectic rats $(\mathrm{T})$ compared with control animals $(\mathrm{Ctl})$. (E) Representative 2D immunoblots corresponding to the detection of MDA-protein adducts in crude muscle homogenates of gastrocnemius (top panels) and heart (bottom panels) of control and cachectic rats (left and right panels, respectively). $\beta$-Enolase (1), creatine kinase (2), carbonic anhydrase-3 (3), actin (4), tropomyosin (5), and ATP synthase (6) were consistently oxidized in the gastrocnemius of both cachectic and control rats. Furthermore, creatine kinase (1), actin (2), tropomyosin (3), myosin-6 (4), myosin light chain (5), vacuolar proton pump (6), ATP synthase (7), NADH-ubiquinone oxidoreductase (8), and aldehyde dehydrogenase mitochondrial (9) were consistently oxidized in the hearts of both cachectic and control rats. Albumin also was modified by MDA in the muscles of both control and cachectic rats (arrows). 
Levels of MDA-protein adducts were also significantly greater in the gastrocnemius, TA, and heart of the cachectic rodents than in the controls (Fig. 2D). Several MDA-protein adducts spots were identified in the skeletal and heart muscles of both tumor-bearing and control rats (Fig. 2E).

Oxidatively modified proteins. Glycolytic enzymes, creatine kinase, carbonic anhydrase-3, contractile, and mitochondrial proteins were identified to be oxidatively modified in the limb and heart muscles of the cachectic and control rats (Tables 2-5). Importantly, enolase, creatine kinase, carbonic anhydrase-3, actin, tropomyosin, and ATP synthase were more intensely oxidized (both reactive carbonyls and MDAprotein adducts) in the gastrocnemius of tumor-bearing rats than in the control muscles (Figs. 3 and 4). Creatine kinase and carbonic anhydrase- 3 were predominantly carbonylated in TA and soleus muscles, respectively, and oxidation levels of carbonic anhydrase- 3 were significantly increased in the cachectic soleus compared with the controls (Figs. 3 and 4). Moreover, tropomyosin was significantly more oxidized (MDA-protein adducts) in TA and soleus, whereas MDAprotein adduct levels of actin and creatine kinase were significantly greater only in TA (Fig. 4). Interestingly, oxidation levels through MDA, but not through reactive carbonyl formation, of creatine kinase, actin, tropomyosin, myosin, vacuolar proton pump, and of mitochondrial enzymes such as ATP-synthase and NADH-ubiquinone oxireductase were significantly greater in the hearts of the cachectic rats than in control animals (Fig. 4). In EDL muscles, levels of carbonylation (reactive carbonyls and MDA-protein adducts) of the identified proteins did not significantly differ between tumorbearing and control rats (Figs. 3 and 4).

Antioxidant mechanisms. The protein content of the mitochondrial enzyme Mn-SOD was significantly greater than that in control animals only in the hearts of tumor-bearing rats (Figs. 4B and 5A). Catalase content was significantly increased in the TA and heart muscles of cachectic rats compared with the controls (Fig. 5C and D).

\section{Muscle structure and its relations with oxidative stress markers}

Morphometric analyses. Proportions of either type I or type II fibers did not significantly differ between tumorbearing and control animals in any of the limb muscles (Fig. 6A). Interestingly, compared with control animals, the size of

Table 2. Identified Carbonylated Proteins in Limb Muscles and Heart of Tumor-Bearing and Control Rats

\begin{tabular}{|c|c|c|c|c|c|}
\hline Muscles & Identified carbonyalted proteins & Accesion no. & Mass & $\begin{array}{c}\text { MASCOT } \\
\text { score }\end{array}$ & $\begin{array}{l}\text { Peptide } \\
\text { matched }\end{array}$ \\
\hline \multirow[t]{7}{*}{ Gastrocnemius } & Beta-enolase & ENOB_RAT & 47.326 & 120 & 16 \\
\hline & Fructose biphosphate aldolase A & ALDOA_RAT & 39.783 & 87 & 9 \\
\hline & Creatine kinase M-type & KCRM_RAT & 43.246 & 151 & 15 \\
\hline & Carbonic anhydrase 3 & CAH3_RAT & 29.698 & 126 & 11 \\
\hline & Actin, alpha skeletal muscle & ACTS_RAT & 42.366 & 93 & 9 \\
\hline & Tropomyosin alpha-1 chain & TPM1_RAT & 32.718 & 190 & 17 \\
\hline & ATP synthase subunit beta, mitochondrial & ATPB_RAT & 56.318 & 167 & 17 \\
\hline \multirow[t]{6}{*}{ Tibialis anterior } & Beta-enolase & ENOB_RAT & 47.326 & 90 & 10 \\
\hline & Fructose biphosphate aldolase A & ALDOA_RAT & 39.783 & 92 & 11 \\
\hline & Creatine kinase M-type & KCRM_RAT & 43.246 & 120 & 10 \\
\hline & Carbonic anhydrase 3 & CAH3_RAT & 29.698 & 66 & 6 \\
\hline & Actin, alpha skeletal muscle & ACTS_RAT & 42.366 & 184 & 16 \\
\hline & Tropomyosin alpha-1 chain & TPM1_RAT & 32.718 & 60 & 7 \\
\hline \multirow{6}{*}{$\begin{array}{l}\text { Extensor digitorum } \\
\text { longus }\end{array}$} & Beta-enolase & ENOB_RAT & 47.326 & 137 & 15 \\
\hline & Fructose biphosphate aldolase A & ALDOA_RAT & 39.783 & 109 & 12 \\
\hline & Creatine kinase M-type & KCRM_RAT & 43.246 & 175 & 15 \\
\hline & Carbonic anhydrase 3 & CAH3_RAT & 29.698 & 78 & 7 \\
\hline & Actin, alpha skeletal muscle & ACTS_RAT & 42.366 & 70 & 7 \\
\hline & ATP synthase subunit beta, mitochondrial & ATPB_RAT & 56.318 & 156 & 18 \\
\hline \multirow[t]{6}{*}{ Soleus } & Fructose biphosphate aldolase A & ALDOA_RAT & 39.783 & 72 & 7 \\
\hline & Creatine kinase M-type & KCRM_RAT & 43.246 & 113 & 11 \\
\hline & Carbonic anhydrase 3 & CAH3_RAT & 29.698 & 90 & 7 \\
\hline & Actin, alpha skeletal muscle & ACTS_RAT & 42.366 & 122 & 12 \\
\hline & Tropomyosin alpha-1 chain & TPM1_RAT & 32.718 & 181 & 19 \\
\hline & ATP synthase subunit beta, mitochondrial & ATPB_RAT & 56.318 & 167 & 17 \\
\hline \multirow[t]{9}{*}{ Heart } & Creatine kinase M-type & KCRM_RAT & 43.246 & 155 & 16 \\
\hline & Actin, alpha cardiac muscle 1 & ACTC_RAT & 42.334 & 82 & 9 \\
\hline & Tropomyosin alpha-1 chain & TPM1_RAT & 32.718 & 131 & 13 \\
\hline & Myosin-6 & MYH6_RAT & 224.168 & 90 & 16 \\
\hline & Myosin light chain & MYL3_RAT & 22.256 & 94 & 9 \\
\hline & Vacuolar proton pump subunit C1 & VATC1_RAT & 44.031 & 59 & 8 \\
\hline & ATP synthase subunit beta, mitochondrial & ATPB_RAT & 56.318 & 170 & 19 \\
\hline & $\begin{array}{l}\text { NADH-ubiquinone oxidoreductase } \\
75 \mathrm{kDa} \text { subunit mitochondrial }\end{array}$ & NDUS1_RAT & 80.331 & 70 & 9 \\
\hline & Aldehyde dehydrogenase mitochondrial & ALDH2_RAT & 56.966 & 56 & 7 \\
\hline
\end{tabular}

Database: SwissProt 56.0. Protein scores $>56$ are significant $(p<0.05)$. 
Table 3. Identified MDA-Protein Adducts in the Limb Muscles and Heart of Tumor-BEARING AND CONTROL RATS

\begin{tabular}{|c|c|c|c|c|c|}
\hline Muscles & Identified MDA-protein adducts & Accesion no. & Mass & $\begin{array}{l}\text { MASCOT } \\
\text { score }\end{array}$ & $\begin{array}{l}\text { Peptide } \\
\text { matched }\end{array}$ \\
\hline \multirow[t]{6}{*}{ Gastrocnemius } & Beta-enolase & ENOB_RAT & 47.326 & 120 & 16 \\
\hline & Creatine kinase M-type & KCRM_RAT & 43.246 & 151 & 15 \\
\hline & Carbonic anhydrase 3 & CAH3_RAT & 29.698 & 126 & 11 \\
\hline & Actin, alpha skeletal muscle & ACTS_RAT & 42.366 & 93 & 9 \\
\hline & Tropomyosin alpha-1 chain & TPM1_RAT & 32.718 & 190 & 17 \\
\hline & ATP synthase subunit beta, mitochondrial & ATPB_RAT & 56.318 & 167 & 17 \\
\hline \multirow[t]{5}{*}{ Tibialis anterior } & Beta-enolase & ENOB_RAT & 47.326 & 90 & 10 \\
\hline & Fructose biphosphate aldolase A & ALDOA_RAT & 39.783 & 92 & 11 \\
\hline & Creatine kinase M-type & KCRM_RAT & 43.246 & 120 & 10 \\
\hline & Actin, alpha skeletal muscle & ACTS_RAT & 42.366 & 184 & 16 \\
\hline & Tropomyosin alpha- 1 chain & TPM1_RAT & 32.718 & 60 & 7 \\
\hline \multirow{5}{*}{$\begin{array}{l}\text { Extensor digitorum } \\
\text { longus }\end{array}$} & Beta-enolase & ENOB_RAT & 47.326 & 137 & 15 \\
\hline & Fructose biphosphate aldolase A & ALDOA_RAT & 39.783 & 109 & 12 \\
\hline & Creatine kinase M-type & KCRM_RAT & 43.246 & 175 & 15 \\
\hline & Actin, alpha skeletal muscle & ACTS_RAT & 42.366 & 70 & 7 \\
\hline & ATP synthase subunit beta, mitochondrial & ATPB_RAT & 56.318 & 156 & 18 \\
\hline \multirow[t]{7}{*}{ Soleus } & Beta-enolase & ENOB_RAT & 47.326 & 76 & 9 \\
\hline & Fructose biphosphate aldolase A & ALDOA_RAT & 39.783 & 72 & 7 \\
\hline & Creatine kinase M-type & KCRM_RAT & 43.246 & 113 & 11 \\
\hline & Carbonic anhydrase 3 & CAH3_RAT & 29.698 & 90 & 7 \\
\hline & Actin, alpha skeletal muscle & ACTS_RAT & 42.366 & 122 & 12 \\
\hline & Tropomyosin alpha-1 chain & TPM1_RAT & 32.718 & 181 & 19 \\
\hline & ATP synthase subunit beta, mitochondrial & ATPB_RAT & 56.318 & 167 & 17 \\
\hline \multirow[t]{9}{*}{ Heart } & Creatine kinase M-type & KCRM_RAT & 43.246 & 155 & 16 \\
\hline & Actin, alpha cardiac muscle 1 & ACTC_RAT & 42.334 & 82 & 9 \\
\hline & Tropomyosin alpha- 1 chain & TPM1_RAT & 32.718 & 131 & 13 \\
\hline & Myosin-6 & MYH6_RAT & 224.168 & 90 & 16 \\
\hline & Myosin light chain & MYL3_RAT & 22.256 & 94 & 9 \\
\hline & Vacuolar proton pump subunit $\mathrm{C} 1$ & VATC1_RAT & 44.031 & 59 & 8 \\
\hline & ATP synthase subunit beta, mitochondrial & ATPB_RAT & 56.318 & 170 & 19 \\
\hline & $\begin{array}{l}\text { NADH-ubiquinone oxidoreductase } \\
75 \mathrm{kDa} \text { subunit mitochondrial }\end{array}$ & NDUS1_RAT & 80.331 & 70 & 9 \\
\hline & Aldehyde dehydrogenase mitochondrial & ALDH2_RAT & 56.966 & 56 & 7 \\
\hline
\end{tabular}

Database: SwissProt 56.0. Protein scores $>56$ are significant $(p<0.05)$.

type II fibers was significantly reduced (33\%) in the gastrocnemius of tumor-bearing rats, whereas the reduction in type I fiber size $(24 \%)$ within the same muscle did not reach the statistical significance (Fig. 6B). In TA, EDL, and soleus muscles, no significant differences were observed between tumorbearing and control animals regarding the size of either type I or type II fibers (Fig. 6B).

Fiber-type composition and oxidative stress. Interestingly, in the gastrocnemius of cachectic animals, the immunohistochemical intensity of reactive carbonyls and MDA-protein adducts was more prominent in type II than in type I fibers of the cachectic rats (Fig. 6C; Tables 6 and 7). Furthermore, type II fibers exhibited a significant increase in the intensity of both reactive carbonyl and MDA-protein adducts staining, as indicated by Hscore 4, in the gastrocnemius of tumor-bearing rats than in control muscles (Fig. 6C; Tables 6 and 7).

\section{Discussion}

In the limb and cardiac muscles of cancer-induced cachectic rats compared with control animals, the following changes were observed: (a) greater protein carbonylation (both HNE- and MDA-protein adducts) levels in the gastrocnemius, TA, soleus, and heart; (b) a significant increase in Mn-SOD in the heart, whereas catalase content was greater in both heart and TA; (c) proteins involved in glycolysis, ATP production and distribution, carbon dioxide hydration, muscle contraction, and mitochondrial metabolism were significantly more oxidized in the limb and heart muscles of the cachectic animals; (d) the size of type II fibers was significantly reduced in the gastrocnemius, but not in the other muscles, of the cachectic animals; and (e) type II fibers of gastrocnemius muscles exhibited a significant increase in protein carbonylation staining in tumor-bearing rats.

\section{Muscle redox balance}

The Yoshida AH-130 ascites hepatoma is a suitable model system for studying the mechanisms involved in cancer cachexia. The growth of the tumor induces a progressive loss of body weight and skeletal muscle proteins in the host. Interestingly, in the tumor-bearing animals, increased muscle protein breakdown involves the activation of the ATPubiquitin-dependent proteolytic pathway (23). In addition to muscle protein loss, muscle DNA is decreased in these animals, leading to DNA fragmentation and apoptosis (47). 
Table 4. Identified Oxidized Proteins in Limb Muscles of Tumor-Bearing and Control Rats

\begin{tabular}{|c|c|c|c|c|c|c|c|}
\hline Muscles & Beta-enolase & Aldolase & Creatine kinase & $\begin{array}{c}\text { Carbonic } \\
\text { anhydrase-3 }\end{array}$ & Actin & Tropomyosin & $\begin{array}{l}\text { ATP synthase } \\
\text { mitochondrial }\end{array}$ \\
\hline \multicolumn{8}{|c|}{ Identified carbonylated proteins } \\
\hline \multicolumn{8}{|l|}{ Gastrocnemius } \\
\hline Control rats & + & + & + & + & + & + & + \\
\hline Tumor-bearing rats & + & + & + & + & + & + & + \\
\hline \multicolumn{8}{|l|}{ Tibialis anterior } \\
\hline Control rats & + & + & + & + & + & + & \\
\hline Tumor-bearing rats & + & + & + & + & + & + & \\
\hline \multicolumn{8}{|c|}{ Extensor digitorum longus } \\
\hline Control rats & + & + & + & + & + & & + \\
\hline Tumor-bearing rats & + & + & + & + & + & & + \\
\hline \multicolumn{8}{|l|}{ Soleus } \\
\hline Control rats & & + & + & + & + & + & + \\
\hline Tumor-bearing rats & & + & + & + & + & + & + \\
\hline \multicolumn{8}{|c|}{ Identified MDA-protein adducts } \\
\hline \multicolumn{8}{|l|}{ Gastrocnemius } \\
\hline Control rats & + & & + & + & + & + & + \\
\hline Tumor-bearing rats & + & & + & + & + & + & + \\
\hline \multicolumn{8}{|c|}{ Extensor digitorum longus } \\
\hline Control rats & + & + & + & & + & & + \\
\hline Tumor-bearing rats & + & + & + & & + & & + \\
\hline \multicolumn{8}{|l|}{ Tibialis anterior } \\
\hline Control rats & + & + & + & & + & + & \\
\hline Tumor-bearing rats & + & + & + & & + & + & \\
\hline \multicolumn{8}{|l|}{ Soleus } \\
\hline Control rats & + & + & + & + & + & + & + \\
\hline Tumor-bearing rats & + & + & + & + & + & + & + \\
\hline
\end{tabular}

The present investigation is the first to provide evidence of the posttranslational modifications induced by ROS on proteins of fast- and slow-twitch fibers in limb and cardiac muscles of rats exposed to cancer-induced cachexia for 7 days. Interestingly, in agreement with our initial hypothesis, protein oxidation, as measured by either HNE- or MDA-protein adducts, was increased in the gastrocnemius, TA, soleus, and heart muscles of the cachectic rats compared with the controls. However, levels of total reactive carbonyls, a marker of direct reaction of multiple forms of ROS with proteins, were significantly greater only in the gastrocnemius of the tumorbearing animals, but not in any of the other limb or heart muscles. In view of these findings, it is possible to conclude that peroxidation of membrane lipids within the myofibers is likely to be a significant contributor to the observed posttranslational oxidative modifications of proteins in limb and cardiac muscles of cachectic rats. Importantly, the current findings also confirm results reported in a previous study in which the redox balance was explored in the gastrocnemius of rats exposed to the Yoshida ascites hepatoma for 7 days (3).

The mitochondrial enzyme Mn-SOD catalyzes the conversion of two superoxide anions into hydrogen peroxide and molecular oxygen. In this study, Mn-SOD protein levels were significantly increased in the heart muscles of tumor-bearing rats, whereas levels of this potent antioxidant did not differ between cachectic and control animals in any of the limb

Table 5. Identified Oxidized Proteins in Heart of Tumor-Bearing and Control Rats

\begin{tabular}{|c|c|c|c|c|c|c|c|c|c|}
\hline Muscles & $\begin{array}{l}\text { Creatine } \\
\text { Kinase }\end{array}$ & Actin & Tropomyosin & Myosin-6 & $\begin{array}{l}\text { Myosin } \\
\text { light } \\
\text { chain }\end{array}$ & $\begin{array}{l}\text { Vacuolar } \\
\text { proton } \\
\text { pump }\end{array}$ & $\begin{array}{l}\text { ATP synthase } \\
\text { mitochondrial }\end{array}$ & $\begin{array}{c}\text { NADH- } \\
\text { ubiquinone } \\
\text { oxidoreductase } \\
\text { mitochondrial }\end{array}$ & $\begin{array}{c}\text { Aldehyde } \\
\text { ehydrogenase } \\
\text { mitochondrial }\end{array}$ \\
\hline
\end{tabular}

Heart

Control rats

Tumor- bearing rats

Identified carbonylated proteins

eart

Control rats

Tumor- bearing rats

$\begin{array}{ll}+ & + \\ + & +\end{array}$

+
+

+
+

Identified MDA-protein adducts

$\begin{array}{ll}+ & + \\ + & +\end{array}$

$\begin{array}{llll}+ & + & + & + \\ + & + & + & +\end{array}$

+
+



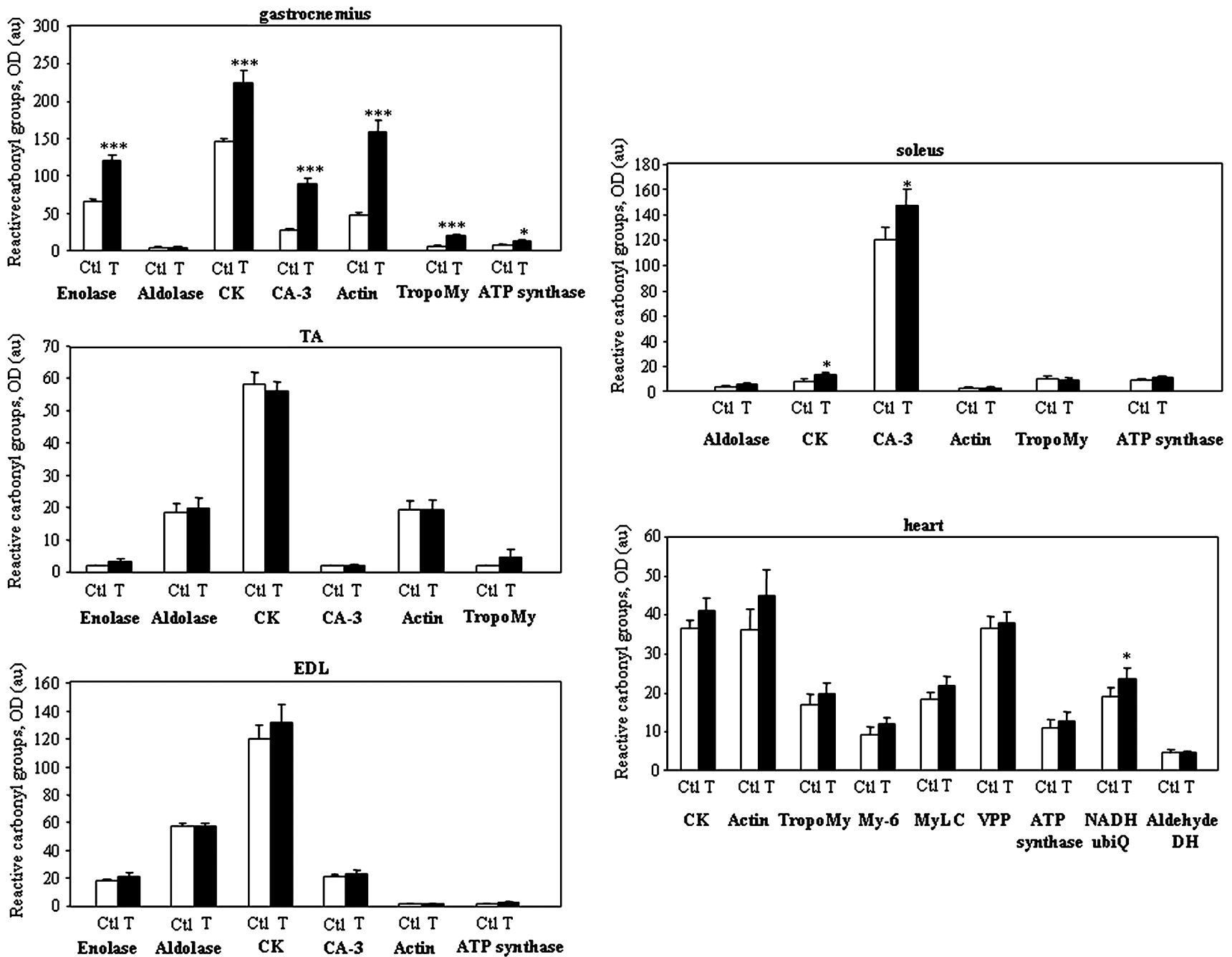

FIG. 3. Mean values and standard deviation of total reactive carbonyls [optical densities (ODs) expressed in arbitrary units (au)] of each identified protein in limb and heart muscles of cachectic and control rats. Note that levels of reactive carbonyls of several muscle proteins [enolase, aldolase, creatine kinase (CK), carbonic anhydrase (CA)-3, actin, tropomyosin (tropoMy), ATP synthase, and NADH-ubiquinone oxidoreductase (NADH-ubiQ)] were significantly greater in gastrocnemius, soleus, and heart, but not TA or EDL, of cachectic rodents than in control animals. Moreover, My-6, myosin light chain (MyLC), vacuolar proton pump (VPP), and aldehyde-dehydrogenase (DH) also were oxidized in the cardiac muscles, without showing significant differences between cachectic and control rats. Statistical significance is expressed as follows: tumor-bearing rats (T) versus control rats $(\mathrm{Ctl}):{ }^{*} p<0.05 ;{ }^{* * *} p<0.001$.

muscles. Catalase is a ubiquitous heme protein with great catalytic activity, responsible for the detoxification of $\mathrm{H}_{2} \mathrm{O}_{2}$ in tissues, together with peroxiredoxins and glutathione peroxidases. Interestingly, in tumor-bearing rats, the heart and TA muscles exhibited a significant increase in catalase content compared with those of control animals. Taken together, these findings may suggest that in cancer cachectic muscles, regulatory mechanisms responsible for the induction of antioxidants, especially of mitochondrial SOD, could be altered $(24,25)$.

In the EDL muscle of tumor-bearing animals, cachexia did not modify any of the oxidative-stress parameters or antioxidant mechanisms, although the muscle exhibited a considerable percentage of weight loss. The specific function of this limb muscle in the rat may explain these findings, because TA, characterized by similar fiber-type composition, exhibited significant increases in protein oxidation (HNE- and MDAprotein adducts) and catalase content in the cachectic animals compared with the control rats. The differences encountered between these two limb muscles may have implications in the design of future studies attempting to explore the specific mechanisms whereby redox imbalance may trigger muscle wasting in different limb muscles of cachectic animals.

\section{Identified oxidized proteins in limb and cardiac muscles}

In the current study, to understand the pathophysiologic consequences of the posttranslational oxidative modifications of muscle proteins, the nature of the oxidatively modified proteins was identified. Importantly, this study is the first to report that proteins involved in glycolysis, ATP production and distribution, carbon dioxide hydration, and muscle con- 

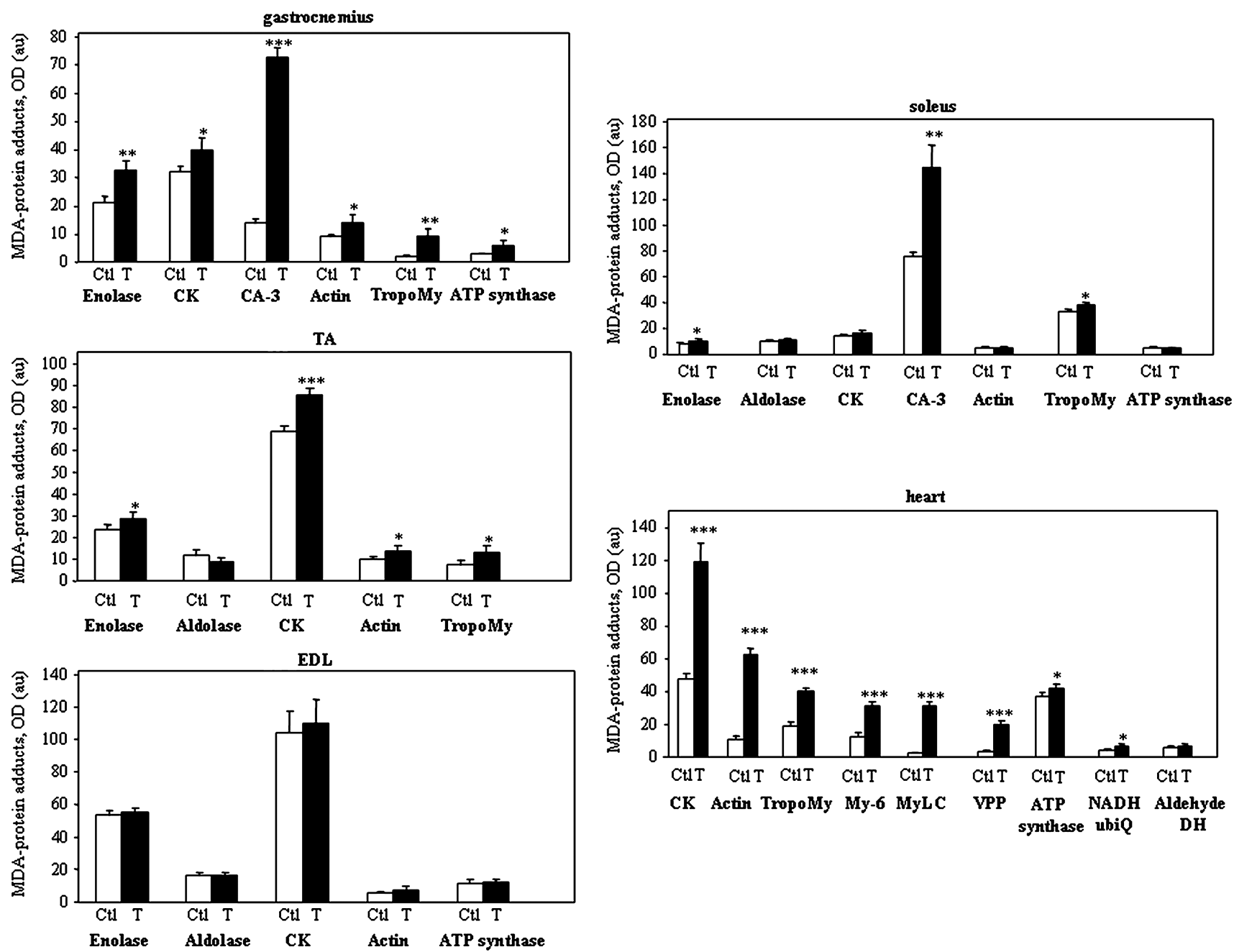

FIG. 4. Mean values (SD) of total MDA-protein adducts [optical densities (OD) expressed in arbitrary units (au)] of each identified protein in limb and heart muscles of cachectic and control rats. Note that levels of MDA-protein adducts of several muscle proteins [enolase, aldolase, creatine kinase (CK), carbonic anhydrase (CA)-3, actin, tropomyosin (tropoMy), ATP synthase, My-6, myosin light chain (MyLC), vacuolar proton pump (VPP), NADH-ubiquinone oxidoreductase (NADHubiQ), and aldehyde-dehydrogenase (DH)] were significantly greater in gastrocnemius, TA, soleus, and heart, but not EDL, of cachectic rodents than in control animals. Statistical significance is expressed as follows: tumor-bearing rats (T) versus control rats $(\mathrm{Ctl}):{ }^{*} p<0.05 ;{ }^{* *} p<0.01 ;{ }^{* * *} p<0.001$.

traction were shown to be significantly more oxidized in limb muscles, especially the gastrocnemius, of cachectic rats than in control rodents. Furthermore, the heart muscles of the tumor-bearing animals also exhibited a significantly increased oxidation (via MDA) of additional proteins such as vacuolar proton pump, NADH-ubiquinone oxidoreductase (mitochondrial respiratory chain complex I), and mitochondrial aldehyde dehydrogenases, which are usually involved in reactive aldehyde detoxification. In view of these findings, it is possible to conclude that in cancer-induced cachexia, muscle proteins are selectively targeted by ROS, and increased protein carbonylation is differentially regulated among limb and heart muscles.

Importantly, previous studies, in which in vivo or in vitro models were used, already demonstrated oxidation of the proteins identified in the present investigation $(8-10,14,15$, $18,19,26,29,32-34,44,45,48,49)$. For instance, we previously showed that glycolytic enzymes, creatine kinase, carbonic anhydrase-3, and $\alpha$-actin were oxidatively modified in the diaphragms of endotoxemic rats $(8,18)$ and in the quadriceps $(9,10)$ and diaphragms of patients with severe COPD (26). In addition, the vacuolar proton-pump enzyme was shown to be inhibited by $\mathrm{H}_{2} \mathrm{O}_{2}$ in brain synaptic vesicles (48). Interestingly, creatine kinase, myosin light chain, ATP synthase, and $\mathrm{NADH}$-ubiquinone oxidoreductase were also identified to be oxidatively modified in rabbit myocardium exposed to ischemia/reperfusion periods (49). In other studies, mitochondrial complex I also was shown to be inactivated $(32,33)$, whereas aldehyde dehydrogenase enzymes were differentially regulated (34) by increased oxidative stress in the rat brain (32) and in gastrocnemius and heart of senescent rats $(33,34)$. It follows that these posttranslational modifications usually occur in critical amino acid residues of proteins sensitive to both selective oxidation and nitration phenomena (45), which may result in either gain (fibrinogen) (15) or loss of 
A

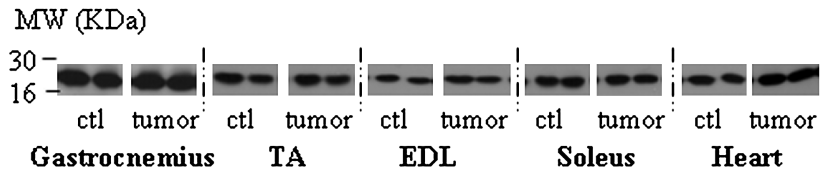

B

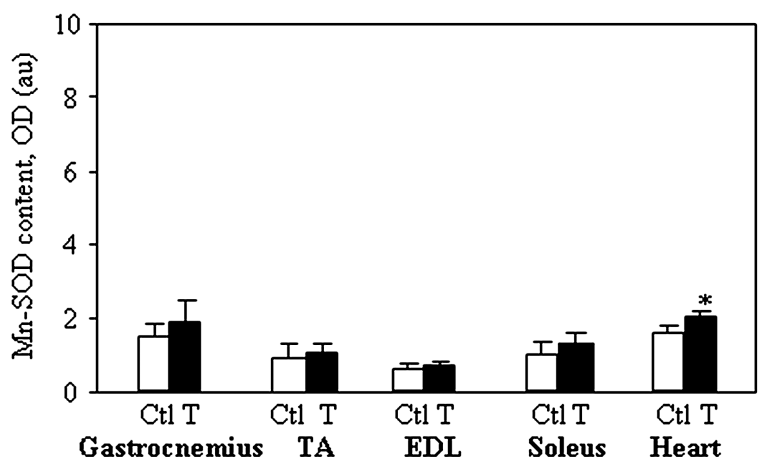

C

$\mathrm{MW}(\mathrm{KDa})$

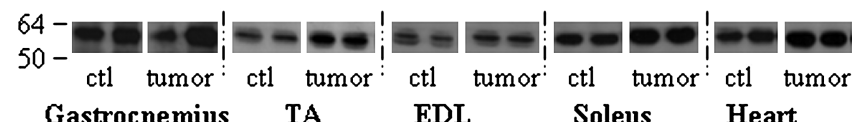

D

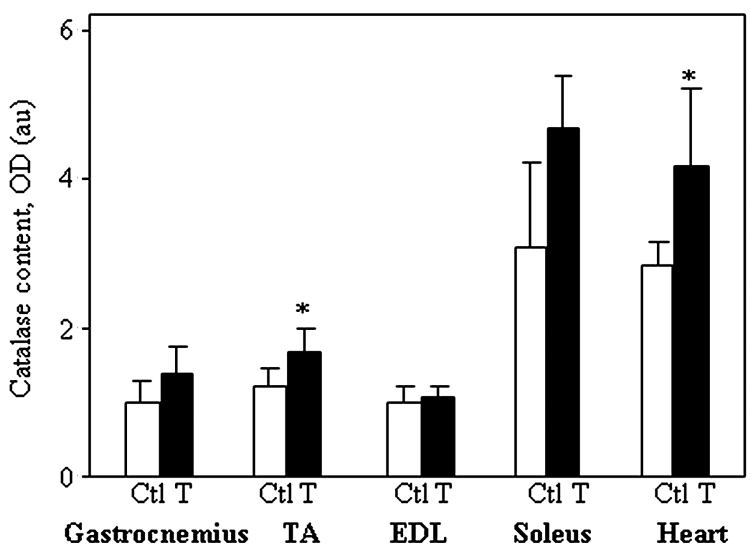

FIG. 5. (A) Representative examples of the different sets of Mn-SOD immunoblots corresponding to the muscles analyzed in the study: gastrocnemius, TA, EDL, soleus, and heart of tumor-bearing and control rats. (B) Mean values and standard deviation of Mn-SOD protein [optical densities (ODs) expressed in arbitrary units (au)] were significantly greater $\left({ }^{*} p<0.05\right)$ only in the heart of cachectic rats $(\mathrm{T})$ compared with control animals $(\mathrm{Ctl})$. (C) Representative examples of the different sets of catalase immunoblots corresponding to the muscles analyzed in the study: gastrocnemius, TA, EDL, soleus, and heart of tumor-bearing and control rats. (D) Mean values and standard deviation of catalase protein [optical densities (ODs) expressed in arbitrary units (au)] were significantly greater $\left.{ }^{*} p<0.05\right)$ only in the TA and heart of cachectic rats $(\mathrm{T})$ compared with control animals (Ctl).
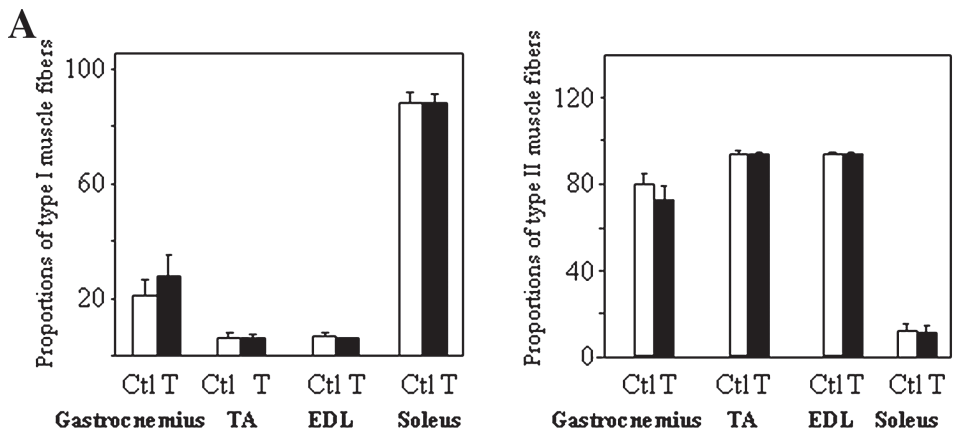

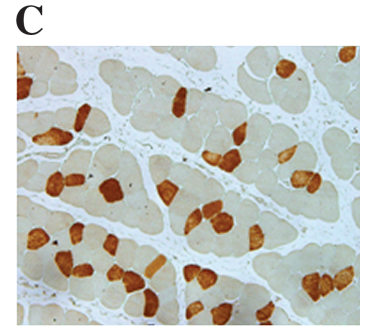

Type I fibers

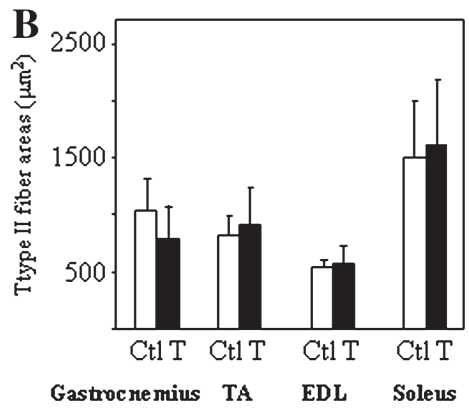

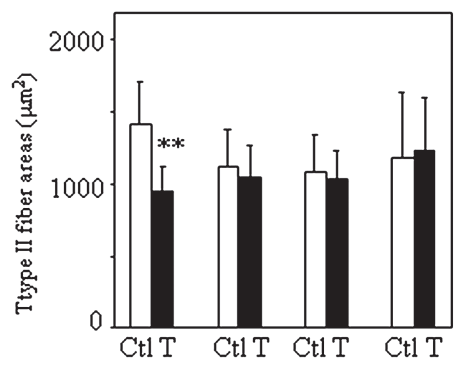

Gastroc nemius TA EDL Soleus

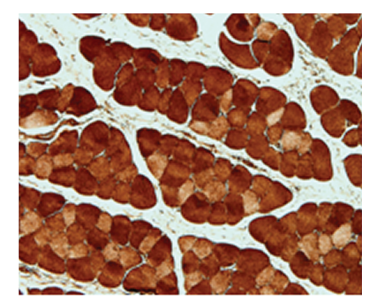

MDA-protein adducts

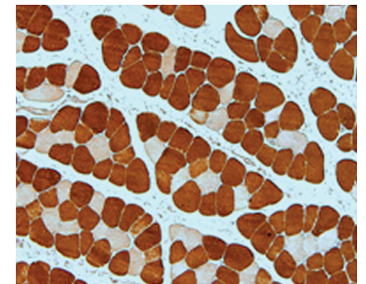

Type II fibers

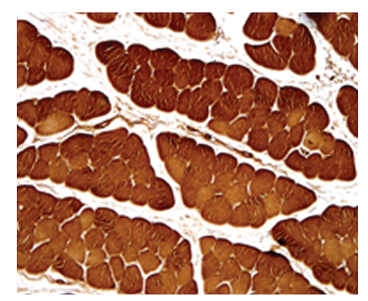

Reactive carbonyls

FIG. 6. (A) Proportions of type I and type II fibers (left and right panels, respectively) did not significantly differ between tumor-bearing $(\mathrm{T})$ and control rats $(\mathrm{Ctl})$ in any of the limb muscles. (B) The size of type I fibers (left panel) did not significantly differ between cachectic and control rats in any of the limb muscles. However, the size of type II fibers (right panel) was significantly reduced $\left(33 \% ;{ }^{* *} p<0.01\right)$ in the gastrocnemius of the tumor-bearing rats $(\mathrm{T})$ compared with the controls $(\mathrm{Ctl})$. $(\mathbf{C})$ Representative examples of type I and type II fibers (left and right top panels, respectively) in the gastrocnemius of a tumorbearing rat. Representative examples of MDA-protein adduct and reactive carbonyl immunostaining in the gastrocnemius of the same tumor-bearing animal (left and right bottom panels, respectively). Note that the staining of both MDA-protein adducts and reactive carbonyls was more prominent within the type II fibers of this limb muscle. (For interpretation of the references to color in this figure legend, the reader is referred to the web version of this article at www.liebertonline.com/ars). 
Table 6. Histochemical Scores Corresponding to Protein Carbonylation Staining in Type I AND Type II Fibers of THE GASTROCNEMiUs Muscle IN RATS

\begin{tabular}{lcc}
\hline & Control & Tumor-bearing \\
\hline Type I fibers, Hscore 0, \% & $1.7(1.4)$ & $1.1(1.5)$ \\
Type II fibers, Hscore 0, \% & 0 & $0.1(0.1)$ \\
Type I fibers, Hscore 1, \% & $58.1(11.8)$ & $48.7(4.9)$ \\
Type II fibers, Hscore 1, \% & $8.1(2.8)$ & $6.3(3.1)$ \\
Type I fibers, Hscore 2, \% & $81.3(3.9)$ & $92.2(16.3)$ \\
Type II fibers, Hscore 2, \% & $145.4(5.6)$ & $129.8(18.8)$ \\
Type I fibers, Hscore 3, \% & $13.5(18.9)$ & $43.2(33.9)$ \\
Type II fibers, Hscore 3, \% & $55.4(14.8)$ & $79.9(38.9)$ \\
Type I fibers, Hscore 4, \% & $2.1(4.2)$ & $2.1(2.8)$ \\
Type II fibers, Hscore 4, \% & $2.9(3.5)$ & $28.6(4.9)^{\mathrm{a}}$ \\
\hline
\end{tabular}

Results are expressed as mean (SD).

Statistical significance of the results: ${ }^{a} p<0.001$, differences in tumor-bearing rats compared to control animals.

protein function $(15,19,24,25,29,32,33,45,48,49)$, as well as in accelerated protein degradation by the proteasome $(31,44)$. Clearly, future studies will shed light on the specific mechanisms whereby the posttranslational oxidative modifications may lead to muscle protein loss or dysfunction or both in cancer-induced cachexia models.

\section{Muscle structure and fiber-type oxidative stress}

The size of fast-twitch fibers was significantly reduced $(33 \%)$ in the gastrocnemius of the cachectic rats compared with control animals. As far as we are concerned, this is the first study in which muscle structure has been explored in both fast- and slow-twitch limb muscles of rats exposed to cancer-induced cachexia. In a previous investigation, soleus muscle fibers from $\mathrm{Apc}^{\mathrm{Min} /+}$ mice also were shown to be of smaller size to those of the control wild-type animals (28). Nonetheless, the structure of the fast-twitch muscles was not explored in that study (28). In the current investigation, limb muscles exhibiting rather pure slow- or fast-twitch phenotypes did not show any significant differences in muscle

Table 7. Histochemical Scores Corresponding to MDA-Protein Adducts Staining in Type I AND TyPe II FibERS OF THE GASTROCNEMIUS Muscle in RAtS

\begin{tabular}{lcc}
\hline & Control & Tumor-bearing \\
\hline Type I fibers, Hscore 0, \% & $17.4(7.6)$ & $9.1(11.1)$ \\
Type II fibers, Hscore 0, \% & $0.9(0.6)$ & 0 \\
Type I fibers, Hscore 1, \% & $54.1(7.2)$ & $54.8(15.4)$ \\
Type II fibers, Hscore 1, \% & $8.3(2.6)$ & $6.1(2.9)$ \\
Type I fibers, Hscore 2, \% & $82.2(9.5)$ & $65.8(19.5)$ \\
Type II fibers, Hscore 2, \% & $55.4(6.3)$ & $52.7(4.7)$ \\
Type I fibers, Hscore 3, \% & $21.6(5.9)$ & $33.4(14.2)$ \\
Type II fibers, Hscore 3, \% & $125.9(8.4)$ & $138.2(35.4)$ \\
Type I fibers, Hscore 4, \% & 0 & $4.8(4.6)$ \\
Type II fibers, Hscore 4, \% & $88.1(7.1)$ & $129.0(18.8)^{\mathrm{a}}$ \\
\hline
\end{tabular}

Results are expressed as mean (SD).

Statistical significance of the results: ${ }^{a} p<0.001$, differences in tumor-bearing rats compared to control animals. structure between tumor-bearing and control rats. Importantly, the present data are consistent with previous observations, in which a loss in the number and size of type II fibers was reported in the vastus lateralis of elderly subjects (20-22). Normal aging is usually associated with sarcopenia, which is characterized by reduced both muscle mass and strength. In this regard, phenotypic changes encountered in senescent muscles may resemble those also occurring in cachectic muscles because of the presence of a malignant disease. Future studies will provide insight into the molecular triggers and signaling pathways leading to protein loss, predominantly in fast-twitch fibers of cachectic animals. It could be concluded, however, that increased protein oxidation may be one upstream mechanism likely involved in protein hypercatabolism or apoptosis or both within fast-twitch fibers in cancerinduced cachexia, because reactive carbonyl and MDAprotein adduct staining was significantly more prominent in type II fibers of the cachectic rats than in control animals. Although we acknowledge that these results must be interpreted cautiously, we also believe that these preliminary findings will serve as the basis for the design of future investigations attempting to explore whether increased oxidative stress leads to type II fiber atrophy and loss in cachectic muscles. Clearly, future studies will shed light on the specific pattern of muscle fiber-type composition observed in cancerinduced cachexia as well as on the similarities or differences (or both) with other chronic conditions also characterized by muscle-mass loss and atrophy.

\section{Study limitations}

A first limitation in this investigation is related to its descriptive nature. However, on the basis of currently available literature, it is not possible to answer the questions that the study addresses. Therefore, our study represents a first attempt to determine whether protein carbonylation is differentially regulated in several skeletal and cardiac muscles of cancer cachectic rodents and whether the carbonylated proteins are selectively targeted in this model. Mechanistic insights into the direct implications of protein carbonylation on muscle atrophy will be clearly provided in future studies.

A second limitation has to do with the lack of functional data in this study. As previously mentioned, a first step in this field of investigation was to explore the specificity of the oxidative phenomena of skeletal and cardiac muscle proteins as well as their differential regulation in cancer cachexia. Future studies will definitely be designed to assess specifically the functional effects of carbonylation on the target proteins as well as its biologic implications on mitochondrial function, muscle metabolism, and contractile properties.

The fact that any respiratory muscle, particularly the diaphragm, was not analyzed in the present investigation constitutes another potential limitation that deserves specific attention. In this regard, at an initial stage of this line of research, we chose to focus selectively on the peripheral muscles, because so far these have been shown to be most affected in cancer cachexia models $(3,12,16,46,47)$. Moreover, the current investigation is somehow an extension of a previously published study (3), in which the gastrocnemius was shown to be severely affected in cancer cachexia, and protein oxidation levels were considerably increased in this muscle. Clearly, in our group, ongoing studies are currently being 
conducted, in which the specificity and differential regulation of protein carbonylation and other indices of oxidative stress, as well as their functional implications, will be widely explored in the diaphragm of rodents exposed to cancerinduced cachexia. Furthermore, corresponding results will be compared with those obtained in the peripheral skeletal and cardiac muscles.

\section{Conclusions}

We conclude that cancer cachexia alters the redox balance in several fast- and slow-twitch limb and heart muscles, inducing significantly increased oxidative modifications of proteins involved in glycolysis, ATP production and distribution, carbon dioxide hydration, muscle contraction, and mitochondrial metabolism. Furthermore, cancer-induced cachexia leads to a reduction in the size of fast-twitch fibers in the gastrocnemius muscle, which is associated with greater protein carbonylation within these fibers.

\section{Acknowledgments}

This study has been supported by FIS 06/1043, FIS 06/0907, FIS CA06/0086, 2005-SGR01060, 2005-SGR00308, and CIBERES (Instituto de Salud Carlos III, Ministerio de Sanidad) (Spain). We thank Miguel-Angel Martínez and Ana Medina for their help with the laboratory experiments, and Roger Marshall, for his editing aid.

\section{Author Disclosure Statement}

All the authors state that no competing financial interests exist.

\section{References}

1. Argiles JM, Alvarez B, and Lopez-Soriano FJ. The metabolic basis of cancer cachexia. Med Res Rev 17: 477-498, 1997.

2. Argiles JM and Lopez-Soriano FJ. The ubiquitin-dependent proteolytic pathway in skeletal muscle: its role in pathological states. Trends Pharmacol Sci 17: 223-226, 1996.

3. Barreiro E, de la PB, Busquets S, Lopez-Soriano FJ, Gea J, and Argiles JM. Both oxidative and nitrosative stress are associated with muscle wasting in tumour-bearing rats. FEBS Lett 579: 1646-1652, 2005.

4. Barreiro E, de la PB, Minguella J, Corominas JM, Serrano S, Hussain SN, and Gea J. Oxidative stress and respiratory muscle dysfunction in severe chronic obstructive pulmonary disease. Am J Respir Crit Care Med 171: 1116-1124, 2005.

5. Barreiro E, Galdiz JB, Marinan M, Alvarez FJ, Hussain SN, and Gea J. Respiratory loading intensity and diaphragm oxidative stress: $N$-acetyl-cysteine effects. J Appl Physiol 100: 555-563, 2006.

6. Barreiro E, Garcia-Martinez C, Mas S, Ametller E, Gea J, Argiles JM, Busquets S, and Lopez-Soriano FJ. UCP3 overexpression neutralizes oxidative stress rather than nitrosative stress in mouse myotubes. FEBS Lett 583: 350-356, 2009.

7. Barreiro E, Gea J, Corominas JM, and Hussain SN. Nitric oxide synthases and protein oxidation in the quadriceps femoris of patients with chronic obstructive pulmonary disease. Am J Respir Cell Mol Biol 29: 771-778, 2003.

8. Barreiro E, Gea J, Di Falco M, Kriazhev L, James S, and Hussain SN. Protein carbonyl formation in the diaphragm. Am J Respir Cell Mol Biol 32: 9-17, 2005.
9. Barreiro E, Gea J, Matar G and Hussain SN. Expression and carbonylation of creatine kinase in the quadriceps femoris muscles of patients with chronic obstructive pulmonary disease. Am J Respir Cell Mol Biol 33: 636-642, 2005.

10. Barreiro E, Rabinovich R, Marin-Corral J, Barbera JA, Gea J, and Roca J. Chronic endurance exercise induces quadriceps nitrosative stress in patients with severe COPD. Thorax 64: 13-19, 2009.

11. Barreiro E, Sanchez D, Galdiz JB, Hussain SN, and Gea J. $N$-acetylcysteine increases manganese superoxide dismutase activity in septic rat diaphragms. Eur Respir J 26: 1032-1039, 2005.

12. Buck M and Chojkier M. Muscle wasting and dedifferentiation induced by oxidative stress in a murine model of cachexia is prevented by inhibitors of nitric oxide synthesis and antioxidants. EMBO J 15: 1753-1765, 1996.

13. Bustamante V, Casanova J, Lopez dS, Mas S, Sellares J, Gea J, Galdiz JB, and Barreiro E. Redox balance following magnetic stimulation training in the quadriceps of patients with severe COPD. Free Radic Res 42: 939-948, 2008.

14. Butterfield DA, Poon HF, St Clair D, Keller JN, Pierce WM, Klein JB, and Markesbery WR. Redox proteomics identification of oxidatively modified hippocampal proteins in mild cognitive impairment: insights into the development of Alzheimer's disease. Neurobiol Dis 22: 223-232, 2006.

15. Gole MD, Souza JM, Choi I, Hertkorn C, Malcolm S, Foust RF III, Finkel B, Lanken PN, and Ischiropoulos H. Plasma proteins modified by tyrosine nitration in acute respiratory distress syndrome. Am J Physiol Lung Cell Mol Physiol 278: L961-L967, 2000.

16. Gomes-Marcondes MC and Tisdale MJ. Induction of protein catabolism and the ubiquitin-proteasome pathway by mild oxidative stress. Cancer Lett 180: 69-74, 2002.

17. Harvey KB, Bothe A Jr, and Blackburn GL. Nutritional assessment and patient outcome during oncological therapy. Cancer 43: 2065-2069, 1979.

18. Hussain SN, Matar G, Barreiro E, Florian M, Divangahi M, and Vassilakopoulos T. Modifications of proteins by 4hydroxy-2-nonenal in the ventilatory muscles of rats. Am J Physiol Lung Cell Mol Physiol 290: L996-L1003, 2006.

19. Koeck T, Levison B, Hazen SL, Crabb JW, Stuehr DJ, and Aulak KS. Tyrosine nitration impairs mammalian aldolase A activity. Mol Cell Proteomics 3: 548-557, 2004.

20. Lexell J. Human aging, muscle mass, and fiber type composition. J Gerontol A Biol Sci Med Sci 50 Spec No: 11-16, 1995.

21. Lexell J and Downham D. What is the effect of ageing on type 2 muscle fibres? J Neurol Sci 107: 250-251, 1992.

22. Lexell J, Taylor CC, and Sjostrom M. What is the cause of the ageing atrophy? Total number, size and proportion of different fiber types studied in whole vastus lateralis muscle from 15- to 83-year-old men. J Neurol Sci 84: 275-294, 1988.

23. Llovera M, Garcia-Martinez C, Agell N, Lopez-Soriano FJ, and Argiles JM. Muscle wasting associated with cancer cachexia is linked to an important activation of the ATPdependent ubiquitin-mediated proteolysis. Int J Cancer 61: 138-141, 1995.

24. MacMillan-Crow LA, Crow JP, Kerby JD, Beckman JS, and Thompson JA. Nitration and inactivation of manganese superoxide dismutase in chronic rejection of human renal allografts. Proc Natl Acad Sci U S A 93: 11853-11858, 1996.

25. MacMillan-Crow LA, Crow JP, and Thompson JA. Peroxynitrite-mediated inactivation of manganese superoxide 
dismutase involves nitration and oxidation of critical tyrosine residues. Biochemistry 37: 1613-1622, 1998.

26. Marin-Corral J, Minguella J, Ramirez-Sarmiento AL, Hussain SN, Gea J, and Barreiro E. Oxidized proteins and superoxide anion production in the diaphragm of severe COPD patients. Eur Respir J 33: 1309-1319, 2009.

27. McCarty KS Jr, Miller LS, Cox EB, Konrath J, and McCarty KS Sr. Estrogen receptor analyses: correlation of biochemical and immunohistochemical methods using monoclonal antireceptor antibodies. Arch Pathol Lab Med 109: 716-721, 1985.

28. Mehl KA, Davis JM, Berger FG, and Carson JA. Myofiber degeneration/regeneration is induced in the cachectic ApcMin/+ mouse. J Appl Physiol 99: 2379-2387, 2005.

29. Mihm MJ, Coyle CM, Schanbacher BL, Weinstein DM, and Bauer JA. Peroxynitrite induced nitration and inactivation of myofibrillar creatine kinase in experimental heart failure. Cardiovasc Res 49: 798-807, 2001.

30. Murr C, Fuith LC, Widner B, Wirleitner B, Baier-Bitterlich G, and Fuchs D. Increased neopterin concentrations in patients with cancer: indicator of oxidative stress? Anticancer Res 19: 1721-1728, 1999.

31. Panda K, Chattopadhyay R, Ghosh MK, Chattopadhyay DJ, and Chatterjee IB. Vitamin C prevents cigarette smoke induced oxidative damage of proteins and increased proteolysis. Free Radic Biol Med 27: 1064-1079, 1999.

32. Petrosillo G, Matera M, Casanova G, Ruggiero FM, and Paradies G. Mitochondrial dysfunction in rat brain with aging Involvement of complex I, reactive oxygen species and cardiolipin. Neurochem Int 53: 126-131, 2008.

33. Petrosillo G, Matera M, Moro N, Ruggiero FM, and Paradies G. Mitochondrial complex I dysfunction in rat heart with aging: critical role of reactive oxygen species and cardiolipin. Free Radic Biol Med 46: 88-94, 2009.

34. Piec I, Listrat A, Alliot J, Chambon C, Taylor RG, and Bechet D. Differential proteome analysis of aging in rat skeletal muscle. FASEB J 19: 1143-1145, 2005.

35. Powers SK, Kavazis AN, and McClung JM. Oxidative stress and disuse muscle atrophy. J Appl Physiol 102: 2389-2397, 2007.

36. Reid MB. Nitric oxide, reactive oxygen species, and skeletal muscle contraction. Med Sci Sports Exerc 33: 371-376, 2001.

37. Reid MB, Khawli FA, and Moody MR. Reactive oxygen in skeletal muscle, III: contractility of unfatigued muscle. J Appl Physiol 75: 1081-1087, 1993.

38. Reid MB, Shoji T, Moody MR, and Entman ML. Reactive oxygen in skeletal muscle, II: extracellular release of free radicals. J Appl Physiol 73: 1805-1809, 1992.

39. Requena JR, Chao CC, Levine RL, and Stadtman ER. Glutamic and aminoadipic semialdehydes are the main carbonyl products of metal-catalyzed oxidation of proteins. Proc Natl Acad Sci USA 98: 69-74, 2001.

40. Requena JR, Fu MX, Ahmed MU, Jenkins AJ, Lyons TJ, and Thorpe SR. Lipoxidation products as biomarkers of oxidative damage to proteins during lipid peroxidation reactions. Nephrol Dial Transplant 11(suppl 5): 48-53, 1996.
41. Requena JR, Levine RL, and Stadtman ER. Recent advances in the analysis of oxidized proteins. Amino Acids 25: 221-226, 2003.

42. Sanchis D, Busquets S, Alvarez B, Ricquier D, Lopez-Soriano FJ, and Argiles JM. Skeletal muscle UCP2 and UCP3 gene expression in a rat cancer cachexia model. FEBS Lett 436: 415-418, 1998.

43. Snead DR, Bell JA, Dixon AR, Nicholson RI, Elston CW, Blamey RW, and Ellis IO. Methodology of immunohistological detection of oestrogen receptor in human breast carcinoma in formalin-fixed, paraffin-embedded tissue: a comparison with frozen section methodology. Histopathology 23: 233-238, 1993.

44. Souza JM, Choi I, Chen Q, Weisse M, Daikhin E, Yudkoff M, Obin M, Ara J, Horwitz J, and Ischiropoulos H. Proteolytic degradation of tyrosine nitrated proteins. Arch Biochem Biophys 380: 360-366, 2000.

45. Souza JM, Daikhin E, Yudkoff M, Raman CS, and Ischiropoulos H. Factors determining the selectivity of protein tyrosine nitration. Arch Biochem Biophys 371: 169-178, 1999.

46. Tessitore L, Costelli P, Bonetti G, and Baccino FM. Cancer cachexia, malnutrition, and tissue protein turnover in experimental animals. Arch Biochem Biophys 306: 52-58, 1993.

47. van Royen M, Carbo N, Busquets S, Alvarez B, Quinn LS, Lopez-Soriano FJ, and Argiles JM. DNA fragmentation occurs in skeletal muscle during tumor growth: a link with cancer cachexia? Biochem Biophys Res Commun 270: 533-537, 2000.

48. Wang $\mathrm{Y}$ and Floor E. Hydrogen peroxide inhibits the vacuolar $\mathrm{H}+$-ATPase in brain synaptic vesicles at micromolar concentrations. J Neurochem 70: 646-652, 1998.

49. White MY, Cordwell SJ, McCarron HC, Prasan AM, Craft G, Hambly BD, and Jeremy RW. Proteomics of ischemia/ reperfusion injury in rabbit myocardium reveals alterations to proteins of essential functional systems. Proteomics 5: 1395-1410, 2005.

50. Wu BJ, Kathir K, Witting PK, Beck K, Choy K, Li C, Croft KD, Mori TA, Tanous D, Adams MR, Lau AK, and Stocker R. Antioxidants protect from atherosclerosis by a heme oxygenase-1 pathway that is independent of free radical scavenging. J Exp Med 203: 1117-1127, 2006.

Address correspondence to: Dr. Esther Barreiro Pulmonology Department-URMAR IMIM-Hospital del Mar PRBB Dr. Aiguader 88 E-08003 Barcelona, Spain

E-mail: ebarreiro@imim.es

Date of first submission to ARS Central, August 12, 2009; date of final revised submission, September 1, 2009; date of acceptance, September 5, 2009. 


\begin{tabular}{|c|}
\hline 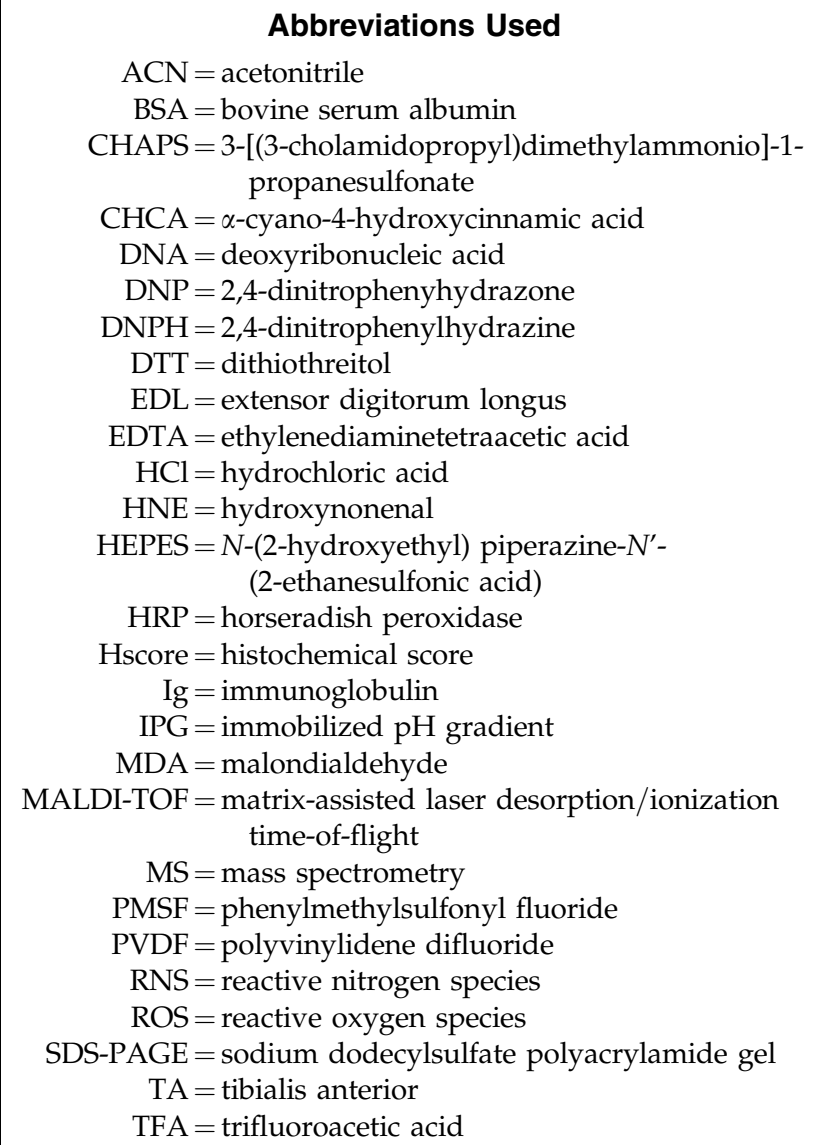 \\
\hline
\end{tabular}

